\title{
Environmental and Cost Advantages of Using Polyethylene Terephthalate Fibre Reinforced Concrete with Fly Ash as a Partial Cement Replacement
}

\author{
Rebecca Belay Kassa ${ }^{1}$, Christopher Kanali' ${ }^{2}$, Nathaniel Ambassah ${ }^{3}$ \\ ${ }^{1}$ Department of Civil Engineering, Pan African University Institute for Basic Sciences, Technology and Innovation (PAUSTI), \\ Nairobi, Kenya \\ ${ }^{2}$ Department of Agricultural and Biosystems Engineering, Jomo Kenyatta University of Agriculture \& Technology (JKUAT), \\ Nairobi, Kenya \\ ${ }^{3}$ Department of Civil Engineering, Jomo Kenyatta University of Agriculture \& Technology (JKUAT), Nairobi, Kenya \\ Email: ‘belayrebecca@gmail.com
}

How to cite this paper: Kassa, R.B., Kanali, C. and Ambassah, N. (2019) Environmental and Cost Advantages of Using Polyethylene Terephthalate Fibre Reinforced Concrete with Fly Ash as a Partial Cement Replacement. Open Journal of Civil Engineering, 9, 281-290.

https://doi.org/10.4236/ojce.2019.94020

Received: September 25, 2019

Accepted: October 26, 2019

Published: October 29, 2019

Copyright $\odot 2019$ by author(s) and Scientific Research Publishing Inc. This work is licensed under the Creative Commons Attribution International License (CC BY 4.0).

http://creativecommons.org/licenses/by/4.0/

\begin{abstract}
Solid waste disposal is an alarming problem in most African countries. Plastic wastes like Polyethylene Terephthalate (PET) bottles and powdered wastes like fly ash are severely persisting environmental hazards. They are brutally polluting the water bodies, landfills, as well as the atmosphere. The construction industry has been working towards improving concrete quality by developing alternative methods like partial cement replacement with different pozzolanic elements as well as using waste fibrous materials. Fly ash and PET bottle fibres are two common waste materials that can be used. This article is a part of a research that studied the combined effects of the addition of PET bottle fibres and fly ash (as a partial cement replacement) on the structural performance of concrete. From a purely engineering point of view, the research results indicate that the utilization and incorporation of PET and fly ash wastes in the construction industry are a viable solution to make concrete quality better. This article presents, beyond the engineering properties and experimental works, the economic and environmental advantages of the addition of these waste materials to the conventional concrete mixture. The addition of PET bottle fibres and fly ash resulted in positive cost implications providing a production cost reduction of $19 \%$ over the conventional concrete mixture. The removal of these materials from the environment also showed reduction of the emission of toxic elements to landfills and water bodies that put human, animal and plant lives in danger.
\end{abstract}




\section{Keywords}

Concrete, PET, Fly Ash, Cost, Environment, Pollution, Landfill

\section{Introduction}

Solid waste disposal is an alarming environmental problem in most African countries. Plastic wastes like Polyethylene Terephthalate (PET) bottles and powdered wastes like fly ash are severely persisting environmental challenges. They are obnoxiously polluting the water bodies, landfills, as well as the atmosphere. This in turn destroys human, animal and plant lives. Recently studies are being done regarding using waste materials in concrete mixes both to improve its quality as well as to benefit the environment. The construction industry has been working towards minimizing the cement usage and improving concrete quality by developing alternative methods like partial cement replacement with different pozzolanic elements as well as using waste fibrous materials. Fly ash and PET bottle fibres are two of the common waste materials that are currently polluting the environment. This article is a part of a research that studied the combined effects of the addition of PET bottle fibres and fly ash (as a partial cement replacement) on the structural performance of concrete. The study investigated the effects of the addition of PET bottles and fly ash on the engineering properties and flexural performance of concrete. PET bottles with an aspect ratio of 50 (100 mm length and $2 \mathrm{~mm}$ width) and fly ash were added to the concrete mix at different percentages and optimized as per the experimental work results. The optimized percentages of PET bottle fibres and fly ash are $1.5 \%$ and $27.5 \%$ by weight of concrete respectively [1] and [2]. From a purely engineering point of view, these results indicate that the utilization and incorporation of PET and fly ash wastes for the improvement of concrete quality are a move in the right direction and are highly recommended. However, other considerations like cost and environmental advantages should be assessed before the materials are used widely.

The environmental and economic advantages of waste minimization and recycling are undeniable as both the environment and the construction industry benefit in terms of pollution and cost reduction respectively. A study by [3] looked into the effects of recycling waste materials (glass, plastic and demolished concrete) and using them in a concrete mix. Alongside the engineering properties, the results of the study showed that there was a significant reduction in cost of waste disposal and construction expenses. Another study by [4] also studied the early age strength development of concrete with the addition of Activator Blast Furnace Slag. The results of this study revealed that the development of early age strength of concrete contributed to the reduction of construction period. This in turn had an economic advantage. The experimental results of compressive strength and sorptivity of PET fibre reinforced 
concrete were given by [5]. Fibres used were made from plastic bottle wastes which are non-biodegradable. The study presented that the addition of waste materials reduced the cost of the plastic fibre reinforced concrete while at the same time resolving the problem of solid waste disposal. It was reported by [6] that the partial cement replacement of concrete using fly ash as a replacing material reduced construction and production costs. The study also underscored that concrete modified with fly ash was more cost effective compared to the conventional ordinary Portland cement concrete.

The other significant benefit of modifying concrete with waste materials is reducing the risks the environment is facing. PET bottles are one of the major non-biodegradable plastic wastes that are considered to be dangerous for the environment. Fly ash again is a by-product of burning coal for energy generation. Because of the chemical it consists, it negatively affects soil, plants, atmosphere and the environment in general if not disposed properly. As this study is proposing to use these products for construction, it is definitely contributing to the benefit of saving the environment from the undesirable effects it is facing.

This article presents, beyond the engineering properties and experimental works, the combined economic and environmental advantages of the addition of PET bottle fibres and fly ash to the conventional concrete mixture. By doing so, it presents the necessary information for further researchers as well as individuals or companies that might want to use these materials in concrete production.

\section{Materials and Methods}

The purpose of this article is to meticulously analyze the actual utilization and management of PET and fly ash wastes by incorporating them in the construction industry and finding out whether or not costs can be saved by adopting a more sustainable and judicious use. It also addresses how much plastic and powdered waste can be collected from the environment reducing a long term risk of pollution. The study was carried out at the Pan African University Institute for Basic Sciences, Technology and Innovation which is hosted at the Jomo Kenyatta University of Agriculture and Technology in Nairobi, Kenya.

\subsection{Cost Implication}

The analysis crystallises into a statement of costs and returns and shows the gains or losses of a relative change in the pattern of use and management of these waste materials in concrete production. This will provide expected change in cost. The analysis takes into account only those changes in costs and returns that result directly from the proposed new practices (s). More precisely, this analysis is concerned with the costs that can be changed by partially replacing cement with fly ash and addition of PET bottle fibers. The major costs in consideration are material costs, transportation costs and labor costs.

The comparison includes the production cost of one cubic metre of conventional concrete to the production cost of the same quantity of concrete modified 
with waste materials (fly ash and PET bottle fibres). Evaluation on cost of concrete production using both methods will be done through preparing the material breakdown for one cubic metre concrete and identifying the unit prices of the materials needed including labour and transportation cost. The comparison will then be based on the cost saving of both types of concrete.

A mix design ratio of 1:1.63:3.13 was used for cement, coarse and fine aggregates respectively in order to carry out the experimental research study. The water to binder ratio used was 0.6. Cement, fly ash, coarse aggregates and fine aggregates were purchased from local distributors. The unit cost for each of these materials including transportation and labour cost was collected from the available price range in the Kenyan market.

PET bottles were collected from the surrounding environment. They were washed, dried and cut into rectangular fibre strips (Figure 1). Only the mid-section of the bottles was used in the process of preparation of the fibres as it is a uniform section. Therefore, the top and bottom sections of the bottles were superfluous (Figure 2). Following this, the amount of fibres acquired from one bottle was five (5) grams. As one bottle on average weighs 18 grams, this leaves 13 grams of cleaned part of the bottle. The cost involved with the PET fibres includes labor cost for collection and cleaning as well as cost for cutting. After extracting the fibres from each bottle, the remaining part was sold to plastic recycling companies. This was considered as an income and was deducted from the cost of PET fibre preparation.

The total cost calculation of each item or service includes the collection of respective unit prices from the available market and multiplying it by the quantity needed to produce one cubic meter of concrete. Equation (1) summarizes the cost calculation for each item or service. In the equation, UP represents unit price, TP represents total price and $\mathrm{Q}$ represents quantity of the items.

\subsection{Environmental Implication}

Waste PET bottles used for packaging of water, soft drinks and other beverages

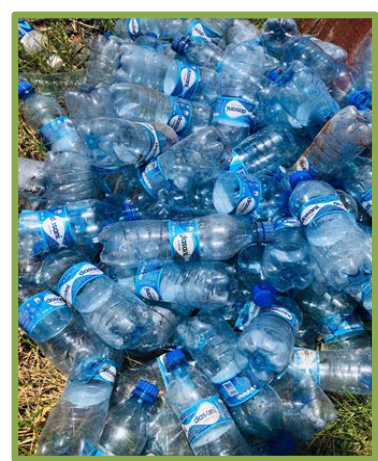

Collecting
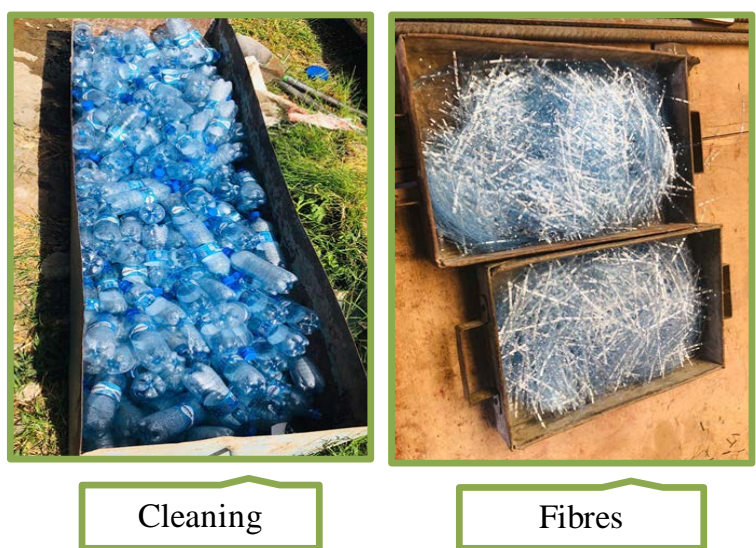

Figure 1. PET fibre preparation. 


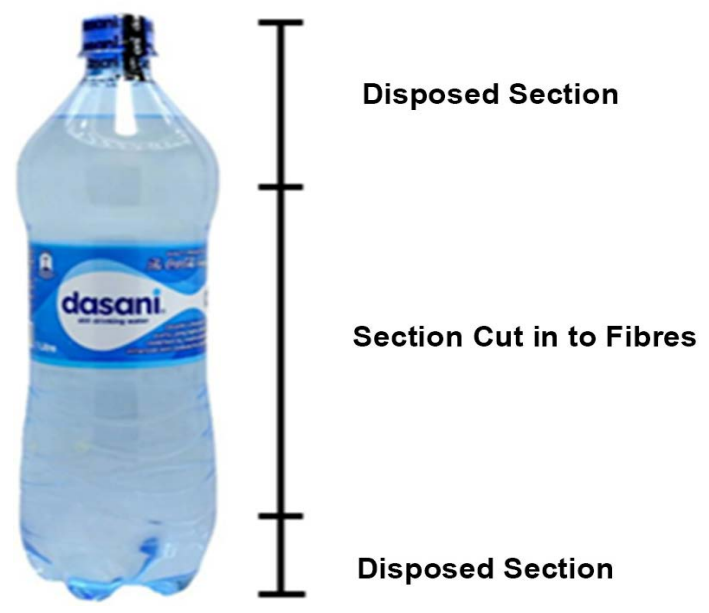

Figure 2. A representation of the parts of the PET bottle that were disposed and used for fibre preparation.

are seen covering the surrounding environment in most African countries. Landfills, sewerage systems as well as water bodies are infested by the abundance of litter from the improperly disposed bottles blocking and clogging sewerage systems, killing animals and destroying marine life once they are ingested [7]. Beyond its physical harm, the improper disposal of PET bottles has a serious chemical impact. Although they can be degraded (broken into smaller portions) due to different environmental factors like the sun and the rain, PET bottles are non-biodegradable (consumed by living organisms). The photo degradation of these bottles releases toxic chemicals in small portions for a very long time. Currently waste plastic bottles are covering and releasing these toxins into water bodies, landfills and the atmosphere in general. This again upsets the environment killing human beings, animals and plants slowly [8].

The assessment of the environmental advantages of using polyethylene terephthalate fibre reinforced concrete with fly ash as a partial cement replacement focuses on the physical and chemical effects of waste PET bottles on the environment and sheds light accordingly on the benefits of using these waste bottles in the construction industry. The physical aspect deals with land and water bodies covered with improperly disposed bottles as well as their ingestion by animals and underwater beings. The chemical aspect on the other hand reveals the toxic chemicals that are released as PET bottles are carelessly disposed in different parts of the environment. It then provides the advantage of recycling the bottles to incorporate them in concrete production.

The rapid industrial development, environmental pollution from the byproducts is becoming a pressing issue. Fly ash generated from the combustion of coal in thermal power plants is usually disposed in the open landfills. It has a high surface concentration of a number of toxic elements. Following its light weight and high atmospheric mobility, the particles of fly ash enter the terrestrial and aquatic environment, making the dissipation of the toxic elements of fly ash 
even a worse [9]. This section also focuses on quantifying the risks of fly ash improperly disposed in the landfills and the advantages of recycling it to be used in the construction industry.

\section{Results and Discussions}

\subsection{Cost Implications}

The cost implications were calculated by comparing the price of preparation of one cubic meter of the conventional concrete with price of preparation of the same volume of the modified concrete. The material breakdown according to the mix design ratio used for this particular study was arranged. Table 1 shows the material compositions needed to produce one cubic meter of both control and modified mixes.

Depending on the material composition needed, the unit prices of each material including labour and transportation were collected from the available Kenyan market. The prices and amounts of coarse aggregate, fine aggregate and water stay the same for both control and modified concrete. The amount needed for purchasing and transporting of the coarse and fine aggregates was taken as per the local distributors' price. The cost of water on the other hand was taken from the tariff set by Nairobi City Water and Sewerage Company. A rapid market appraisal survey was done interviewing five local distributors within the available market and it revealed that the average price of each of the materials needed per kilogram. Accordingly, Table 2 and Table 3 give the summary of costs related to each material for control and modified concrete mixes respectively.

The cost of binder (cement and fly ash) needed to produce one cubic meter of concrete decreased by $19.25 \%$ for the modified concrete as compared to the control concrete. This is due to partial (27.5\%) cement replacement by fly ash. The price of one (1) kilogram of cement including transportation and offloading costs is $28 \mathrm{KSh}$ while the price of the same amount of fly ash including transportation and offloading costs is $8.4 \mathrm{KSh}$. This shows that fly ash is a cost effective alternative to cement.

Table 1. Material composition for the preparation of one cubic meter of conventional concrete and one cubic meter of modified concrete.

\begin{tabular}{ccc}
\hline Material & Modified Mix $\left(\mathrm{kg} / \mathrm{m}^{3}\right)$ & Control Mix $\left(\mathrm{kg} / \mathrm{m}^{3}\right)$ \\
\hline Cement & 266.15 & 367.11 \\
Fly ash & 100.95 & - \\
Coarse aggregate & 1150 & 1150 \\
Fine aggregate & 583 & 583 \\
Water & 221.26 & 221.26 \\
PET fibres & 5.51 & - \\
\hline
\end{tabular}


Table 2. Quantity and price of materials to prepare one cubic meter of control concrete.

\begin{tabular}{lccc}
\hline \multicolumn{1}{c}{ Type and description of Material } & $\begin{array}{c}\text { Unit price per Kg } \\
\left(\text { Kenyan Shillings }{ }^{\mathrm{a}}\right)\end{array}$ & $\begin{array}{c}\text { Quantity } \\
(\mathrm{Kg})\end{array}$ & $\begin{array}{c}\text { Total Price } \\
(\text { Kenyan Shillings) }\end{array}$ \\
\hline $\begin{array}{l}\text { Ordinary Portland Cement, delivered } \\
\text { and offloaded }\end{array}$ & 28 & 367.11 & $10,279.08$ \\
Fly ash, delivered and offloaded & - & - & - \\
Coarse aggregate, delivered and offloaded & 3 & 1,150 & 3450 \\
Fine aggregate, delivered and offloaded & 2.5 & 583 & 1457.5 \\
$\quad$ Water & 0.053 & 221.26 & 11.73 \\
PET fibres, collection, cleaning and cutting & - & - & - \\
$\quad$ Total & & & $15,198.31$ \\
\hline
\end{tabular}

a. The current official exchange rate is 1 USD $=100$ Kenyan Shillings.

Table 3. Quantity and price of materials to prepare one cubic meter of modified concrete.

\begin{tabular}{|c|c|c|c|}
\hline Type and description of Material & $\begin{array}{l}\text { Unit price per Kg } \\
\text { (Kenyan Shillings) }\end{array}$ & $\begin{array}{l}\text { Quantity } \\
\text { (Kg) }\end{array}$ & $\begin{array}{c}\text { Total Price } \\
\text { (Kenyan Shillings) }\end{array}$ \\
\hline $\begin{array}{l}\text { Ordinary Portland Cement, delivered and } \\
\text { offloaded }\end{array}$ & 28 & 266.15 & 7452.2 \\
\hline Fly ash, delivered and offloaded & 8.4 & 100.95 & 847.98 \\
\hline Coarse aggregate, delivered and offloaded & 3 & 1150 & 3450 \\
\hline Fine aggregate, delivered and offloaded & 2.5 & 583 & 1457.5 \\
\hline Water & 0.053 & 221.26 & 11.73 \\
\hline PET fibres, collection, cleaning and cutting & 100 & 5.51 & 551 \\
\hline Extra PET bottle to be sold & -70 & 14.326 & 1002.82 \\
\hline Total & & & $12,767.59$ \\
\hline
\end{tabular}

PET bottles that were collected from the surrounding environment had costs of collection, cleaning and cutting into rectangular fibres. This particular research used manual method of cutting the bottles into fibres therefore, machine cutting costs are not included. The labor cost was 100 Kenyan Shillings per one (1) kilogram of PET fibres. Only the mid-section of the bottle was used for extracting the fibres. The remaining top and bottom sections were sold to recycling companies instead of disposing them back into the environment. This was also considered as money returned and deducted from the labor cost for collection and processing of PET bottles.

Generally, the total cost of production of one cubic meter of conventional concrete mix as per the mix design used was 15,198.31 KSh while the modified concrete mix would require $12,767.59 \mathrm{KSh}$ for production. Thus, by using polyethylene terephthalate fibre reinforced concrete with fly ash as a partial cement replacement to produce one cubic meter of modified conrete $2430.72 \mathrm{KSh}$ was saved. Therefore, beyond the improvement in performance of concrete, the addition of PET bottle fibres and fly ash has positive cost implications providing a 
production cost reduction of $19 \%$. This goes in line with conclusions drawn by [3] [4] [5] [6].

\subsection{Environmental Implications}

\subsubsection{PET Bottle Fibres}

The material composition for the production of one (1) cubic meter of the concrete modified with PET fibres and fly ash as per the mix design ratio of this study requires $5.51 \mathrm{Kg}$ of PET fibres. Five (5) grams of fibres can be extracted from one bottle. This makes the total number of bottles collected from the environment to produce one (1) cubic meter of concrete 1,102 which is about 20 kilograms (including the sections of the bottles that are not used to cut fibres from).

In December 2018 [10] published Kenya PET Recycling company's statement testifying the annual production of PET in Kenya is 20,000 tons and only 1000 tons (5\%) is recycled. The remaining waste bottles end up layering landfills, clogging sewerage systems and covering water bodies. Instead of being used for a valuable purpose, the land covered by the excessive waste PET bottles is left to be polluted by the toxic chemicals emitted during the photo degradation of the bottles. When dumped to landfill, they disrupt the natural production of enzymes in the soil. This interrupts the fertility of the soil causing a serious issue in the agricultural sector. The polluting chemicals that are released include heavy metals like Cadium and Lead as well as chemicals as Benzene and Dioxin. Beyond this leachate is produced in landfills leaking into surface and ground water. This in turn risks human and animal health [8]. Animals and marine life exposed to these waste bottles on the other hand ingest them and end up choking or failing to digest or even get entangled.

Different ways of disposing PET bottles and their life cycle sustainability assessment were looked up by [11]. One of these practiced disposal ways of PET bottles in the study was landfills. It was based on the disposal of 1 tonne of PET bottles as a functional unit. It showed the landfilling scenario was the only scenario to negatively affect human health, ecosystem quality and resources. This made disposal of PET bottles to the landfill the worst scenario at hand. Based on this information alongside other studies, this study used an approach to reduce the impact in the environment. The collection of 20 kilograms of PET bottles from the surrounding just to produce one (1) cubic meter of concrete is an essential move towards the recycling of these bottles as well as improving concrete behavior. The incorporation of these bottles in the construction industry gives room for the landfill reducing the possibility of pollution.

\subsubsection{Fly Ash}

The production of one (1) cubic meter of modified concrete as per this study requires 100.95 kilograms of fly ash. This removes a great deal of fly ash from the landfills. It is a critical solution to prevent the environment from excessive pollution by improperly disposed fly ash. Fly ash is composed of harmful heavy metals like arsenic, lead, nickel, cobalt, chromium, boron and antimony. The 
Table 4. Concentration of heavy metals in fly ash.

\begin{tabular}{cc}
\hline Element & Concentration per Kg of Fly ash $(\mathrm{mg} / \mathrm{kg})$ \\
\hline Chromium $(\mathrm{Cr})$ & $87-103$ \\
Manganese $(\mathrm{Mn})$ & $47-139$ \\
Lead $(\mathrm{Pb})$ & $20-56$ \\
Zinc $(\mathrm{Zn})$ & $60-124$ \\
Copper $(\mathrm{Cu})$ & $56-83$ \\
Nickel $(\mathrm{Ni})$ & $28-63$ \\
Cobalt $(\mathrm{Co})$ & $8-18$ \\
\hline
\end{tabular}

emission of these elements to soil, surface and ground water by the leaching process has a massive impact on human, animal and plant lives [12]. The ash content of fly ash and the constituent elements were delivered by. [13]. It revealed the concentration of toxic heavy metals per kilogram of fly ash. Table 4 shows this concentration as presented by [13].

The study further discussed the release of these metals to the environment would mean plant and animals are exposed to them and through time it gets through the food chain, which disrupts the whole ecosystem.

Therefore, this study has a potential to contribute to the environment by removing 100.95 kilograms of fly ash and in turn preventing the heavy metals from being emitted.

\section{Conclusion}

This paper looked at the cost and environmental advantages of incorporating PET bottle fibres and fly ash to a conventional concrete mix. From the results, the addition of PET bottle fibres and fly ash as a partial replacement of cement showed positive cost implications, reducing the production cost for one cubic meter of concrete by $19 \%$. Similarly, the collection of improperly disposed PET bottles and fly ash from the surrounding environment to be used in the construction industry safeguards animals, plants and human beings. It reduces the emission of toxic elements to landfill and water bodies. Therefore, beyond the improvements on the structural performance of the concrete, PET bottle fibres and fly ash have positive cost and environmental advantages if used as concrete constituent materials. It can safely be concluded that the combination of the two materials can be a way forward in the production of concrete.

\section{Conflicts of Interest}

The authors declare no conflicts of interest regarding the publication of this paper.

\section{References}

[1] Kassa, R.B., Kanali, C. and Ambassah, N. (2019) Engineering Properties of Polye- 
thylene Terephthalate Fibre Reinforced Concrete with Fly Ash as a Partial Cement Replacement. Civil and Environmental Research, 11, 25-34.

[2] Kassa, R.B., Kanali, C. and Ambassah, N. (2019) Flexural Performance Evaluation of Polyethylene Terephthalate Fibre Reinforced Concrete with Fly Ash as a Partial Cement Replacement. IJERT, 12, 1435-1440.

[3] Batayneh, M., Marie, I. and Asi, I. (2006) Use of Selected Waste Materials in Concrete Mixes. Waste Management, 27, 1870-1876. https://doi.org/10.1016/j.wasman.2006.07.026

[4] Tae, H.K. (2016) Assessment of Construction Cost Saving by Concrete Mixing the Activator Material. Building and Urban Research Institute, Korea Institute of Civil Engineering and Building Technology, Korea.

[5] Nibudey, R.N., Nagarnaik, P.B., Parbat, D.K. and Pande, A.M. (2014) Compressive Strength and Sorptivity Properties of PET Fiber Reinforced Concrete. International Journal of Advances in Engineering \& Technology, 7, 1206-1216.

[6] Ahmaruzzaman, M. (2010) A Review on the Utilization of Fly Ash. Progress in Energy and Combustion Science, 36, 327-363.

https://doi.org/10.1016/j.pecs.2009.11.003

[7] WHO (2019) Microplastics in Drinking Water.

[8] Pavani, P. and Rajeswari, R. (2014) Impact of Plastics on Environmental Pollution. Journal of Chemical and Pharmaceutical Sciences, 2014, 2087-2093.

[9] Jena, S. (2011) Environmental Impacts of Fly Ash Generated from a Coal Fired Power Plant in Indian Sub-Continent.

[10] Kenya Targets to Recycle 14,000 Tonnes of Plastic Bottles. https://www.google.com/amp/s/www.standardmedia.co.ke/mobile/amp/article/200 $\underline{1305050 / \text { kenya-targets-to-recycle-14-000-tonnes-of-plastic-bottles }}$

[11] Foolmaun, R.K. and Ramjeawon, T. (2013) Life Cycle Sustainability Assessments (LCSA) of Four Disposal Scenarios for Used Polyethylene Terephthalate (PET) Bottles in Mauritius. Environment, Development and Sustainability, 15, 783-806. https://doi.org/10.1007/s10668-012-9406-0

[12] Suresh, I.V., Padmakar, C., Prabha, P., Murthy, M.V.R.L., Raju, C.B., Yadava, R.N. and Venkata Rao, K. (1998) Effect of Pond Ash on Ground Water Quality: A Case Study. Environmental Management and Health, 9, 200-208. https://doi.org/10.1108/09566169810240508

[13] Sushil, S. and Batra, V.S. (2006) Analysis of Fly Ash Heavy Metal Content and Disposal in Three Thermal Power Plants in India. Fuel, 85, 2676-2679. https://doi.org/10.1016/j.fuel.2006.04.031 